\title{
Quantitative ultrasound does not identify patients with an inflammatory disease at risk of vertebral deformities
}

\author{
A Caroline Heijckmann*1,2, Bianca Dumitrescu ${ }^{3,4}$, Arie C Nieuwenhuijzen \\ Kruseman ${ }^{1}$, Piet Geusens ${ }^{4,5}$, Bruce HR Wolffenbuttel ${ }^{6}$, Jolanda De Vries ${ }^{7}$, \\ Marjolein Drent ${ }^{8,9}$ and Maya SP Huijberts ${ }^{1}$
}

Address: ${ }^{1}$ Department Internal Medicine, Division of Endocrinology, University Hospital Maastricht, The Netherlands, ${ }^{2}$ Department of Internal Medicine, Hospital Bernhoven Veghel/Oss, The Netherlands, ${ }^{3}$ Department of Rheumatology, University of medicine and Pharmacy "Çarol Davila", Bucharest, Romania, ${ }^{4}$ Department of Rheumatology, University Hospital Maastricht, The Netherlands, ${ }^{5}$ Biomedical Research Institute, University Hasselt, Belgium and Nutrition and Toxicology Research Institute Maastricht (NUTRIM), The Netherlands, ${ }^{6}$ Department of Endocrinology, University Medical Center Groningen and University of Groningen, The Netherlands, ${ }^{7}$ Department of Medical Psychology, Tilburg University and St. Elisabeth Hospital Tilburg, The Netherlands, ${ }^{8}$ Department of Respiratory Medicine, University Hospital Maastricht, The Netherlands and ${ }^{9}$ Sarcoidosis Management Team, University Hospital Maastricht, The Netherlands

Email: A Caroline Heijckmann* - caroline@ heesen.eu; Bianca Dumitrescu - bia1mar@yahoo.com; Arie C Nieuwenhuijzen Kruseman - a.kruseman@intmed.unimaas.nl; Piet Geusens - p.geusens@scarlet.be; Bruce HR Wolffenbuttel - bwo@int.umcg.nl; Jolanda De Vries - j.devries@uvt.nl; Marjolein Drent - m.drent@hetnet.nl; Maya SP Huijberts - mhuij@sint.azm.nl

* Corresponding author

Published: 20 May 2008

BMC Musculoskeletal Disorders 2008, 9:72 doi:10.1186/147I-2474-9-72
Received: 9 July 2007

Accepted: 20 May 2008

This article is available from: http://www.biomedcentral.com/I47/-2474/9/72

(c) 2008 Heijckmann et al; licensee BioMed Central Ltd.

This is an Open Access article distributed under the terms of the Creative Commons Attribution License (http://creativecommons.org/licenses/by/2.0), which permits unrestricted use, distribution, and reproduction in any medium, provided the original work is properly cited.

\begin{abstract}
Background: Previous studies from our group have shown that a high prevalence of vertebral deformities suggestive of fracture can be found in patients with an inflammatory disease, despite a near normal bone mineral density (BMD). As quantitative ultrasound (QUS) of the heel can be used for refined assessment of bone strength, we evaluated whether QUS can be used to identify subjects with an inflammatory disease with an increased chance of having a vertebral fracture.
\end{abstract}

Methods: 246 patients (mean age: $44 \pm 12.4$ years) with an inflammatory disease (sarcoidosis or inflammatory bowel disease (IBD)) were studied. QUS of the heel and BMD of the hip (by dual Xray absorptiometry (DXA)) were measured. Furthermore lateral single energy densitometry of the spine for assessment of vertebral deformities was done. Logistic regression analysis was performed to assess the strength of association between the prevalence of a vertebral deformity and BMD and QUS parameters, adjusted for gender and age.

Results: Vertebral deformities (ratio of $<0.80$ ) were found in 72 vertebrae of 54 subjects $(22 \%)$. In contrast to the QUS parameters BUA (broadband ultrasound attenuation) and SOS (speed of sound), T-score of QUS and T-scores of the femoral neck and trochanter (DXA) were lower in the group of patients with vertebral deformities. Logistic regression analysis showed that the vertebral deformity risk increases by about 60 to $90 \%$ per I SD reduction of BMD (T-score) determined with DXA but not with QUS.

Conclusion: Our findings imply that QUS measurements of the calcaneus in patients with an inflammatory condition, such as sarcoidosis and IBD, are likely of limited value to identify patients with a vertebral fracture. 


\section{Background}

Osteoporosis is a skeletal disease characterized by low bone mass and microarchitectural deterioration resulting in increased bone fragility and hence susceptibility to fracture $[1,2]$. The benchmark for the diagnosis of osteoporosis is the assessment of bone mineral density (BMD) with dual energy X-ray absorption (DXA) [2], as it is well established that the risk of future fracture rises with the decline of BMD. However, low BMD alone is not the only determinant of fracture risk [3] and it is evident that assessment of fracture risk should encompass all aspects of risk and not be guided exclusively by results of bone mineral density measurements [4]. In addition, in several conditions BMD evaluation provides a modest prediction of fracture risk. For example, the use of glucocorticoids (GCs) is a substantial risk factor for future fractures, which is largely independent of BMD $[5,6]$.

We reported recently that a high prevalence of vertebral deformities suggestive of fracture can be found in patients who are considered at risk for secondary osteoporosis due to an inflammatory disease, such as sarcoidosis and inflammatory bowel disease (IBD), despite a near normal BMD [7]. This may imply that bone strength is decreased in patients with inflammatory diseases, and that changes in bone microarchitecture rather than low BMD result in an increased fracture risk $[8,9]$.

The last years there has been increasing interest in Quantitative Ultrasound (QUS) methods for refined assessment of bone strength [10]. This noninvasive technique may assess microarchitecture and elasticity in addition to bone mineral density [11]. Several studies have demonstrated that QUS of the heel can predict fracture comparable to and independent of spine and femur BMD, and that it can be used to identify patients with higher risk [12-15]. Compared with DXA, QUS is less expensive, portable, does not require specially trained personnel and does not employ ionizing radiation.

To evaluate whether QUS can indeed be used to identify subjects likely to have a vertebral fracture irrespective of changes in BMD, we performed QUS on our series of subjects with sarcoidosis and IBD [7] and compared the results with results of vertebral fracture assessment and BMD measurements with DXA.

\section{Subjects and methods Patients}

Between January 2002 and July 2003, all patients with inflammatory bowel disease or sarcoidosis who had a disease duration of at least one year, and attended the outpatient clinic of the University Hospital Maastricht, were asked to participate in this cross-sectional study. Sixteen patients with known causes of bone mass abnormalities, such as renal failure, thyroid dysfunction, alcoholism, long-term anticoagulant use and ankylosing spondylitis were excluded. Thirty-six patients were excluded because of the use of bisphosphonates or hormone replacement therapy.

Finally, 246 patients were included (mean age: $44 \pm 12.4$ years) of which 87 were diagnosed with sarcoidosis and 159 with inflammatory bowel disease. All patients were Caucasians and diagnosed with sarcoidosis according to the WASOG guidelines [16], based on consistent clinical features and results of an analysis of bronchoalveolar lavage fluid [17] or with CD $(n=95)$ or UC $(n=64)$ on clinical grounds using endoscopic and/or radiological evidence, and by histological investigation of mucosal biopsies and/or surgical specimens when available. For confirmation of the CD diagnosis the Lennard-Jones criteria [18] and for UC the Truelove and Witts criteria [19] were applied.

Table I: Demographic, treatment variables and clinical risk factors in the study patients $(n=246)$.

\begin{tabular}{lc}
\hline Variable & Total group (n = 246) \\
\hline Age (years) & $44 \pm 12.4$ \\
Males/premenopausal women/postmenopausal women & $109 / 103 / 34(44 / 42 / 14)$ \\
Body mass index $\left(\mathrm{kg} / \mathrm{m}^{2}\right)$ & $25.5 \pm 4.7$ \\
Sarcoidosis/CD/UC & $87 / 95 / 64(35 / 39 / 26)$ \\
Disease duration (years) & $6(1-36)$ \\
GC use never/previous/current & $74 / 124 / 48(30 / 50 / 20)$ \\
Daily dose GC current group & $12.9(2.5-39)$ \\
Fracture $>50$ years, number & $2 / 83(2)$ \\
Vertebral deformity by DXA & $54(22)$ \\
Low body weight $(<60 \mathrm{~kg})$ & $44(18)$ \\
Low physical activity index $\leq 5$ & $53(22)$ \\
Mother with hip deformity & $16(7)$
\end{tabular}

Data are given as mean \pm SD, median (range) or number (\%). Abbreviations: CD, Crohn's disease; UC, ulcerative colitis; GC, glucocorticoid; DXA, dual-energy X-ray absorptiometry. 
The clinical records of all patients were reviewed. Demographic, clinical and treatment data of these patients are summarized in table 1. No patients were on bisphosphonates.

Patients were evaluated according to a standard protocol that included questionnaires related to known clinical risk factors for osteoporosis (weight below $60 \mathrm{~kg}$, hip fracture in the mother, history of fractures after age 50, menopausal status and severe immobilization) [20], calcium intake, physical activity [21], measurement of height and weight and measurement of BMD. Glucocorticoid therapy was evaluated by means of a patient questionnaire and verified using all the records of the patient's pharmacist. Informed consent was obtained from all participants and this study was approved by the ethical committee of the hospital.

\section{Bone mineral density and morphometry}

QUS and DXA measurements were performed. QUS was performed in the left calcaneus using a Sahara device (Hologic, Waltham, MA, USA). This equipment measures the broadband ultrasound attenuation (BUA) $(\mathrm{dB} / \mathrm{MHz})$ and the speed of sound (SOS) $(\mathrm{m} / \mathrm{sec})$ in a fixed region of interest in the central calcaneal zone. The device combines the values of BUA and SOS to yield a parameter known as the "quantitative ultrasound index" (QUI) or stiffness, based on the following equation: QUI $=0.41 *(\mathrm{BUA}+$ SOS) -571. The QUI is also expressed as a T-score (reference data were those provided by the manufacturer). The heel of each patient was measured three times with complete repositioning between measurements. The definitive result was the mean of these three measurements. The coefficient of variation (CV) of the QUI was $1.4 \%$. The instrument was subjected to daily quality control using a phantom provided by the manufacturer.

BMD of the hip was measured by dual energy X-ray absorption (DXA, Hologic QDR 4500, NHANES-III reference group). The hip was measured in the standard projection, and results are reported for femoral neck and trochanter. Standard procedures supplied by the manufacturer for scanning and analysis were performed. Calibration with the manufacturer's spine phantom and quality control analysis was performed daily. The CV for BMD measurements was $1.0 \%$. Furthermore, after bone density measurement a lateral single energy densitometry of the thoracic and lumbar spine for vertebral fracture assessment (VFA) was performed (also called Morphometric Xray absorptiometry (MXA)) [22]. The scans obtained were analyzed twice by one trained operator (BD) (intraobserver coefficient of variation: 0.85 ), using the quantitative method of Genant [23]. The observer was blinded to the T-score values and to the values of the first set of measurements. After visual examination six points were placed on each vertebral body from T4 to L4. From these points three vertebral heights were measured anterior (Ha), mid (Hm) and posterior (Hp); On the basis of the average score of these morphometric measurements ratios were calculated and a prevalent vertebral deformity was defined as a reduction of height of $20 \%$ or more ( $\mathrm{Ha} / \mathrm{Hp}$; $\mathrm{Hm} / \mathrm{Hp}$ and $\mathrm{Hp} / \mathrm{Hp}$ below) [23]. Severity of deformities was assessed according to the method of Genant [23]. A score of ' 0 ' was assigned to normal, non-fractured vertebra; ' 1 ' for a mild deformity $(20-25 \%$ reduction in anterior, middle or posterior vertebral height); ' 2 ' for a moderate deformity (25-40\% reduction) and ' 3 ' for a severe deformity ( $>40 \%$ reduction).

\section{Statistical analysis}

Student t-tests, chi-square tests, and one-way ANOVAs were used, depending on the variables and subgroups tested. Logistic regression analyses was performed to assess the strength of association between the prevalence of a vertebral deformity (dependent variable) and BMD and QUS parameters (BMD femoral neck or BMD trochanter or QUI), adjusted for gender and age (covariates). A p-value $<0.05$ was considered statistically significant. Analyses were performed with SPSS version 12.0.

\section{Results}

As summarized in table 1, our series consisted of 103 premenopausal women, 34 post-menopausal women, and 109 men. The mean age $( \pm$ SD) of this group of patients was $44 \pm 12$. 4 years and this was similar in both sarcoidosis and IBD. With QUS, the broadband ultrasound attenuation (BUA) value was higher in men than in women (78 \pm 16 versus $73 \pm 15 \mathrm{~dB} / \mathrm{MHz}, \mathrm{p}<0.005)$. No differences between the sexes of the other QUS parameters were found. The T- or Z-scores of FN or trochanter determined with DXA were not different between the sexes as well.

T-scores of femoral neck and/or trochanter determined with DXA were in the osteopenic (T-score $<-1$ and $>-2.5$ ) or osteoporotic $(\leq-2.5)$ range in respectively $50 \%$ and $2 \%$ of the patients studied, in total in $52 \%$. In contrast, QUS of the calcaneus revealed a T-score below -1 in 32\% of the patients. Correlations between DXA and QUS T-scores were $\mathrm{r}=0.35$ for the $\mathrm{T}$-score of the quantitative ultrasound index (QUI) with the T-score of the femoral neck ( $\mathrm{p}<$ 0.001 ) (figure 1) and $r=0.36$ for the T-score QUI with the T-score of the trochanter $(\mathrm{p}<0.001)$.

Clinical non-vertebral fractures had occurred in two postmenopausal women. Vertebral deformities with VFA (ratio of $<0.80$ ) were found in 72 vertebrae of 54 subjects $(22 \%)$ with a higher prevalence in men $(32 \%)$ than in women $(14 \%)$. Sixty-one of these were wedge and 9 biconcave deformities. Two crush deformities were seen. Multiple vertebral deformities were observed in $6 \%$ of the 


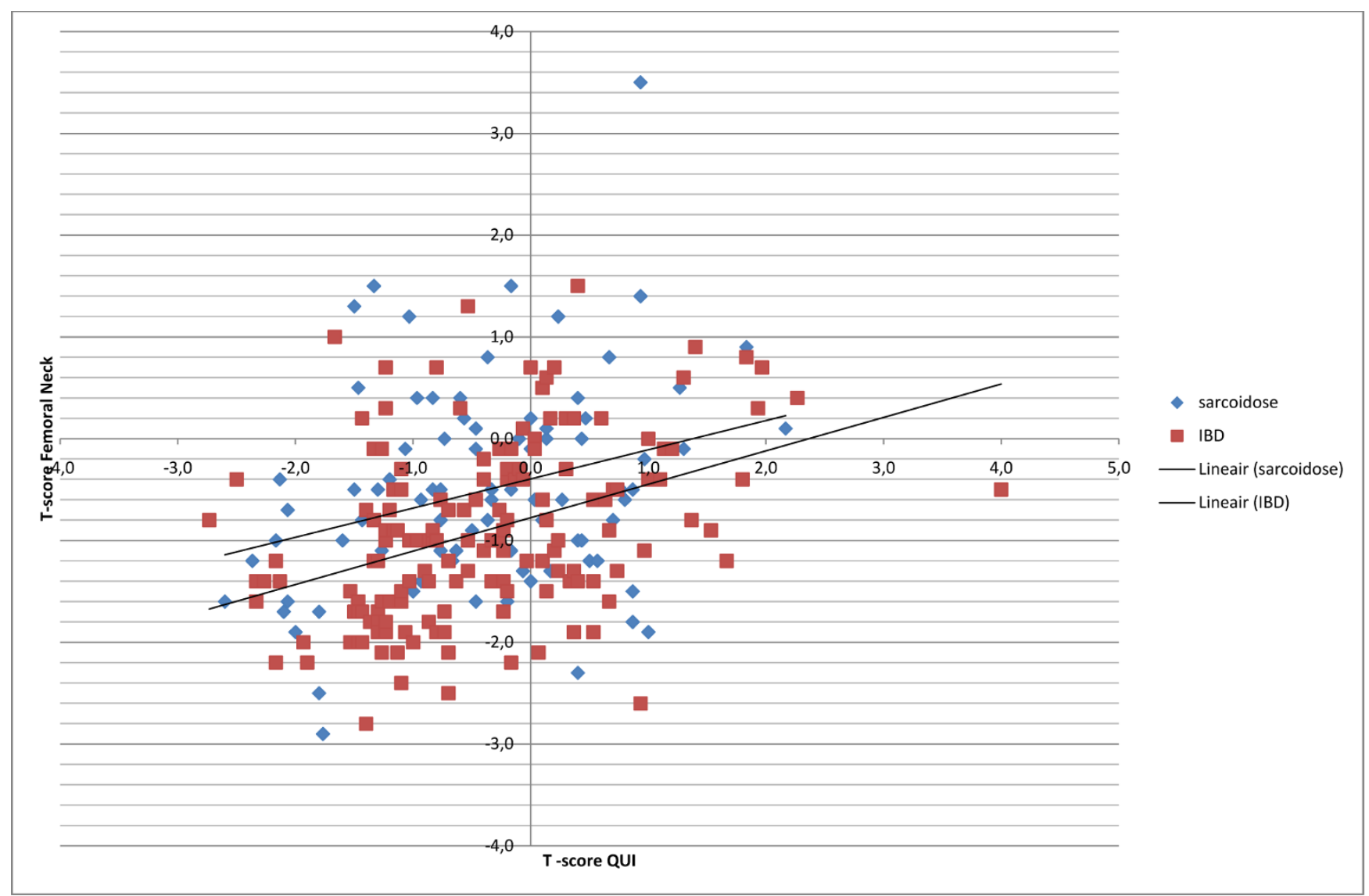

Figure I

T-score Femoral neck (DXA) versus T-score QUI (QUS). DXA, dual energy X-ray absorption; QUI, quantitative ultrasound index; QUS, quantitative ultrasound; IBD, inflammatory bowel disease.

Table 2: Bone variables in patients with and without any vertebral deformity, measured morphometrically.

\begin{tabular}{|c|c|c|c|c|}
\hline & Without deformity (192) & With any deformity (54) & All & $\mathbf{P}^{*}$ \\
\hline \multicolumn{5}{|l|}{ DXA variables } \\
\hline Femoral neck $\left(\mathrm{g} / \mathrm{cm}^{2}\right)$ & $0.80 \pm 0.12$ & $0.76 \pm 0.10$ & $0.79 \pm 0.11$ & 0.006 \\
\hline - T-score & $-0.66 \pm 0.9$ & $-1.16 \pm 0.8$ & $-0.77 \pm 0.9$ & $<0.001$ \\
\hline • Z-score & $-0.13 \pm 1.0$ & $-0.43 \pm 0.9$ & $-0.20 \pm 1.0$ & 0.06 \\
\hline Trochanter $\left(\mathrm{g} / \mathrm{cm}^{2}\right)$ & $0.72 \pm 0.13$ & $0.69 \pm 0.10$ & $0.71 \pm 0.13$ & 0.2 \\
\hline - T-score & $-0.21 \pm 1.0$ & $-0.51 \pm 0.8$ & $-0.27 \pm 1.0$ & 0.04 \\
\hline - Z-score & $0.05 \pm 1.1$ & $-0.16 \pm 0.8$ & $0.00 \pm 1.0$ & 0.2 \\
\hline \multicolumn{5}{|l|}{ QUS variables } \\
\hline$\overline{\mathrm{BUA}(\mathrm{dB} / \mathrm{MHz})}$ & $76 \pm 16$ & $73 \pm 14$ & $75 \pm 16$ & 0.2 \\
\hline $\operatorname{SOS}(\mathrm{m} / \mathrm{s})$ & $1545 \pm 89$ & $153 \mid \pm 99$ & $1542 \pm 92$ & 0.3 \\
\hline QUI & $103 \pm 45$ & $94 \pm 16$ & $10| \pm 4|$ & 0.1 \\
\hline T-score & $-0.34 \pm 1.1$ & $-0.65 \pm 0.9$ & $-0.41 \pm 1.0$ & 0.04 \\
\hline
\end{tabular}

Data are given as mean \pm SD or number (\%); * p between patients with and without vertebral deformity;

Abbreviations: DXA, dual energy X-ray absorption; QUS, quantitative ultrasound; BUA, broadband ultrasound attenuation; SOS, speed of sound; QUI, quantitative ultrasound index. 
entire cohort and 7\% had one or more moderate or severe deformities.

In table 2 data of BMD measurements with DXA and QUS in the group of patients with or without vertebral deformities are summarized. Relative to the patients without vertebral deformities, those with vertebral deformities were on average older. The former group comprised more women, the latter more men. T-scores but not Z-scores of the femoral neck and trochanter (DXA) were lower in the group of patients with vertebral deformities. The T-score of the calcaneus (QUS) was also lower in this group of patients. No differences for the other ultrasound parameters were found between the groups with or without vertebral deformities. Furthermore, no differences were found in clinical risk factors, for the different diseases, GC use, disease duration, BMI, physical activity, calcium intake, current use of calcium and/or vitamin D supplements, aminosalicylates, immunosuppressive medication, and budenoside.

Table 3 gives odds ratios (OR) per unit T-score reduction (per SD) for any vertebral deformity for the three separate regression analyses. The vertebral deformity risk increases by about 60 to $90 \%$ per 1 SD reduction determined with DXA but not with QUS. When both BMD of the femoral neck and QUI are entered simultaneously in the regression analysis the respective OR's are $1.81(1.18-2.75, \mathrm{p}$ $=0.006)$ for BMD-FN and $1.09(0.77-1.56, \mathrm{p}=0.623)$ for QUI.

\section{Discussion}

Our study shows that in a group of patients with an inflammatory disease as sarcoidosis and inflammatory bowel disease (IBD) none of the QUS variables had added value to recognize patients with a prevalent vertebral deformity suggestive of fracture.

In several other studies QUS has been compared with DXA in patients with IBD. Robinson and coworkers [24] studied 100 patients with Crohn's disease (CD) and 52 age-matched controls and found lower values of both BUA and SOS in CD. The correlation between BUA and

Table 3: Odds ratios* for any vertebral deformity of various bone measurements adjusted for gender and age in patients with an inflammatory disease

\begin{tabular}{lccc}
\hline & OR & $95 \% \mathrm{Cl}$ & $P$ \\
\hline BMD femoral neck & 1.88 & $1.26-2.81$ & 0.002 \\
BMD trochanter & 1.63 & $1.12-2.37$ & 0.01 \\
QUI & 1.31 & $0.95-1.81$ & $\mathrm{Ns}$ \\
\hline
\end{tabular}

Abbreviations: OR, odds ratio; $\mathrm{Cl}$, confidence interval; $\mathrm{BMD}$, bone mineral density; QUI, quantitative ultrasound index.

* OR per one unit T-score reduction (per SD)
BMD-values determined at the hip and spine with DXA was, however, insufficient to recommend QUS as a screening tool. In another study, 53 patients with CD and 57 with ulcerative colitis (UC) were included and QUS variables (BUA and SOS) were compared with DXA-measurements of the hip and lumbar spine [25]. Although this study also revealed a correlation between the QUS variables and DXA ( $r=0.50$ to 0.67$)$, the agreement between measurements in individual patients was poor. Similar observations were made in two other studies on patients either with CD or UC $[26,27]$. No studies with QUS have been performed in patients with sarcoidosis.

A shortcoming of all the reported studies on the value of QUS in IBD is of course that they used BMD determined by DXA as gold standard, assuming that fracture risk increases with a decrease in BMD as in subjects without inflammatory conditions. No assessment of clinical and prevalent vertebral fractures was done. In our series, vertebral deformities suggestive of non-clinical fractures were found in $22 \%$ of patients. The T-scores of these patients determined by both DXA and QUS were on average lower than those in patients without vertebral deformities. Although there was a correlation between T-scores determined with QUS and DXA, this correlation was moderate, as found by others [28]. In addition, the calculated Odds ratios for any vertebral deformity per unit T-score reduction was increased for BMD of the hip (DXA) but not for the QUI of the calcaneus. This supports the view that the predictive value of QUS in patients with inflammatory conditions is poor. On the other hand, a limitation of our series is the moderate number of patients with one or more deformities suggestive for vertebral fracture. It is therefore possible that our study did not have adequate power to delineate an association between QUS and vertebral fractures.

Our findings are in contrast with several large prospective studies that have shown that QUS of the calcaneus can predict fracture risk nearly as good as DXA [12-14]. These studies are, however, all studies in elderly women and involve prediction of clinical (mainly non-vertebral) fractures. Kanis explored the relationship between QUS-determinations at the phalanges with age and the probability of symptomatic vertebral fractures and concluded that the 10 -year probability of clinical vertebral fractures above the age of 45 increased for each SD decrease in measurement of SOS and fast wave amplitude (RR 1.7 , respectively 2.4/SD) [29]. Studies on morphometric vertebral deformities and QUS parameters are, however, scarce. In 764 postmenopausal women (mean age $73 \pm 6.4$ years) the prevalence of nontraumatic vertebral fractures assessed with DXA was compared with an age matched control group with normal morphometry and this study showed that heel QUS enabled discrimination of women with 
fracture from those without [30]. The same findings were reported in another study in postmenopausal women with rheumatoid arthritis [31]. On the other hand, other studies revealed no differences in patients with and without a prevalent vertebral deformity. In one cross-sectional study in 551 post-menopausal women (mean age $65.2 \pm$ 13.1) receiving chronic glucocorticoid therapy a high prevalence of asymptomatic morphometric vertebral fractures was found (37\%), without any difference in QUS measurements between patients with and without deformities [32]. This indicates that if QUS may be of any value to predict fracture risk, this will be in postmenopausal women and not in the type of patients included in our study.

Although the T-scores of patients with vertebral deformities of our series were lower than in those without, the Zcores were not different. This means that the differences in $\mathrm{T}$-score are likely due to differences in age rather than differences in disease activity. In addition, despite the fact that the T-scores were lower, they were certainly not diagnostic for osteoporosis, indicating that in inflammatory conditions, an increased fracture risk is due to changes in bone strength that are not combined with changes in BMD [7].

\section{Conclusion}

In our hands QUS measurements of the calcaneus in patients with an inflammatory condition, such as sarcoidosis and IBD, were not associated with prevalent vertebral deformities and are therefore likely not of value to recognise patients at risk for fracture. Hence, we feel that both BMD measurement with DXA and vertebral fracture assessment are better methods to identify such patients. Follow-up studies are, however, needed to substantiate this view.

\section{Competing interests}

Performance of the study was supported by an unrestricted educational grant from Merck Sharpe and Dome, the Alliance for Better Bone Health and Eli Lilly. The authors declare that they have no competing interest.

\section{Authors' contributions}

ACH coordinated study concept and design, performed acquisition, analysis and interpretation of data and prepared the manuscript. BD analyzed the scans for vertebral fracture assessment and took part in manuscript preparation. ACNK and PG took part in interpretation of data and preparation of the manuscript. BHRW was involved in study concept and design and preparation of the final manuscript. JDV performed analysis, interpretation of data and preparation of the final manuscript. MD did acquisition of subjects, interpretation of data and preparation of the final manuscript. MSPH was involved in anal- ysis and interpretation of data and preparation of the manuscript. All authors read and approved the final manuscript.

\section{Acknowledgements}

The authors wish to thank Mrs. Dany Simon, Mrs. Esther ten Hoor, Mrs. Gé van Kan and Mrs. Petal Wijnen for their help with the data collection.

\section{References}

I. Cummings SR, Melton LJ: Epidemiology and outcomes of osteoporotic fractures. Lancet 2002, 359:| I6I-I767.

2. Assessment of fracture risk and its application to screening for postmenopausal osteoporosis. Report of a WHO Study Group. World Health Organ Tech Rep Ser 1994, 843: I- 129.

3. Schuit SC, van der KM, Weel AE, de Laet CE, Burger H, Seeman E, Hofman A, Uitterlinden AG, van Leeuwen JP, Pols HA: Fracture incidence and association with bone mineral density in elderly men and women: the Rotterdam Study. Bone 2004, 34:195-202.

4. Kanis JA, Borgstrom F, De Laet C, Johansson H, Johnell O, Jonsson B, Oden A, Zethraeus N, Pfleger B, Khaltaev N: Assessment of fracture risk. Osteoporos Int 2005, I 6:581-589.

5. Kanis JA, Johansson H, Oden A, Johnell O, de LC, Melton III LJ, Tenenhouse A, Reeve J, Silman AJ, Pols HA, Eisman JA, McCloskey EV, Mellstrom D: A meta-analysis of prior corticosteroid use and fracture risk. J Bone Miner Res 2004, 19:893-899.

6. van Staa TP, Geusens P, Bijlsma JW, Leufkens HG, Cooper C: Clinical assessment of the long-term risk of fracture in patients with rheumatoid arthritis. Arthritis Rheum 2006, 54:3 I04-3 I I 2.

7. Heijckmann AC, Huijberts MS, De Vries J, Menheere PP, van der Veer E, Nieuwenhuijzen Kruseman AC, Wolffenbuttel BH, Geusens P, Drent $M$ : Bone turnover and bone mineral density in patients with sarcoidosis. Sarcoidosis Vasc Diffuse Lung Dis 2007 in press.

8. Seeman E, Delmas PD: Bone quality--the material and structural basis of bone strength and fragility. N Engl J Med 2006, 354:2250-226I.

9. Chavassieux P, Seeman E, Delmas PD: Insights into material and structural basis of bone fragility from diseases associated with fractures: how determinants of the biomechanical properties of bone are compromised by disease. Endocr Rev 2007, 28: I5 I- 164.

10. Gluer CC: Quantitative Ultrasound--it is time to focus research efforts. Bone 2007, 40:9-13.

II. Njeh CF, Fuerst T, Diessel E, Genant HK: Is quantitative ultrasound dependent on bone structure? A reflection. Osteoporos Int 2001, I 2:1-15.

12. Bauer DC, Gluer CC, Cauley JA, Vogt TM, Ensrud KE, Genant HK, Black DM: Broadband ultrasound attenuation predicts fractures strongly and independently of densitometry in older women. A prospective study. Study of Osteoporotic Fractures Research Group. Arch Intern Med 1997, I 57:629-634.

13. Hans D, rgent-Molina P, Schott AM, Sebert JL, Cormier C, Kotzki PO, Delmas PD, Pouilles JM, Breart G, Meunier PJ: Ultrasonographic heel measurements to predict hip fracture in elderly women: the EPIDOS prospective study. Lancet 1996, 348:5||-5|4.

14. Pluijm SM, Graafmans WC, Bouter LM, Lips P: Ultrasound measurements for the prediction of osteoporotic fractures in elderly people. Osteoporos Int 1999, 9:550-556.

15. Pongchaiyakul C, Panichkul S, Songpatanasilp T, Nguyen TV: A nomogram for predicting osteoporosis risk based on age, weight and quantitative ultrasound measurement. Osteoporos Int 2007, | 8:525-53|.

16. Hunninghake GW, Costabel U, Ando M, Baughman R, Cordier JF, du BR, Eklund A, Kitaichi M, Lynch J, Rizzato G, Rose C, Selroos O, Semenzato G, Sharma OP: ATS/ERS/WASOG statement on sarcoidosis. American Thoracic Society/European Respiratory Society/World Association of Sarcoidosis and other Granulomatous Disorders. Sarcoidosis Vasc Diffuse Lung Dis 1999, 16:149-173.

17. Drent M, Jacobs JA, Cobben NA, Costabel U, Wouters EF, Mulder PG: Computer program supporting the diagnostic accuracy 
of cellular BALF analysis: a new release. Respir Med 200I, 95:78I-786.

18. Lennard-Jones JE: Classification of inflammatory bowel disease. Scand J Gastroenterol Suppl 1989, 170:2-6.

19. Truelove SC, Witts LI): Cortisone in ulcerative colitis; preliminary report on a therapeutic trial. Br Med J 1954, 2:375-378.

20. CBO KG: Osteoporose: tweede herziene richtlijn. 2002.

21. Elders PJ, Netelenbos JC, Lips P, Khoe E, Van Ginkel FC, Hulshof KF, Van der Stelt PF: Perimenopausal bone mass and risk factors. Bone Miner 1989, 7:289-299.

22. Duboeuf F, Bauer DC, Chapurlat RD, Dinten JM, Delmas P: Assessment of vertebral fracture using densitometric morphometry. J Clin Densitom 2005, 8:362-368.

23. Genant HK, Wu CY, van KC, Nevitt MC: Vertebral fracture assessment using a semiquantitative technique. J Bone Miner Res 1993, 8: II37-I|48.

24. Robinson RJ, Carr I, lqbal SJ, al-Azzawi F, Abrams K, Mayberry JF: Screening for osteoporosis in Crohn's disease. A detailed evaluation of calcaneal ultrasound. Eur J Gastroenterol Hepatol 1998, 10:137-|40.

25. Jahnsen J, Falch JA, Mowinckel P, Aadland E: Ultrasound measurements of calcaneus for estimation of skeletal status in patients with inflammatory bowel disease. Scand J Gastroenterol 1999, 34:790-797.

26. Fries W, Dinca M, Luisetto G, Peccolo F, Bottega F, Martin A: Calcaneal ultrasound bone densitometry in inflammatory bowel disease--a comparison with double x-ray densitometry of the lumbar spine. Am J Gastroenterol 1998, 93:2339-2344.

27. Schwartz DA, Connolley CD, Koyama T, Wise PE, Herline AJ: Calcaneal ultrasound bone densitometry is not a useful tool to screen patients with inflammatory bowel disease at high risk for metabolic bone disease. Inflamm Bowel Dis 2005, I I:749-754.

28. Nayak S, Olkin I, Liu H, Grabe M, Gould MK, Allen IE, Owens DK, Bravata DM: Meta-analysis: accuracy of quantitative ultrasound for identifying patients with osteoporosis. Ann Intern Med 2006, I44:832-84I.

29. Kanis JA, Johnell O, Oden A, De Laet C, de TF: Ten-year probabilities of clinical vertebral fractures according to phalangeal quantitative ultrasonography. Osteoporos Int 2005 16:1065-1070.

30. Frediani B, Acciai C, Falsetti P, Baldi F, Filippou G, Siagkri C, Spreafico $A$, Galeazzi M, Marcolongo R: Calcaneus ultrasonometry and dual-energy $\mathrm{X}$-ray absorptiometry for the evaluation of vertebral fracture risk. Calcif Tissue Int 2006, 79:223-229.

31. Orstavik RE, Haugeberg G, Uhlig T, Mowinckel P, Kvien TK, Falch JA Halse Jl: Quantitative ultrasound and bone mineral density: discriminatory ability in patients with rheumatoid arthritis and controls with and without vertebral deformities. Ann Rheum Dis 2004, 63:945-95I.

32. Angeli A, Guglielmi G, Dovio A, Capelli G, de FD, Giannini S, Giorgino $R$, Moro L, Giustina A: High prevalence of asymptomatic vertebral fractures in post-menopausal women receiving chronic glucocorticoid therapy: a cross-sectional outpatient study. Bone 2006, 39:253-259.

\section{Pre-publication history}

The pre-publication history for this paper can be accessed here:

http://www.biomedcentral.com/1471-2474/9/72/prepub
Publish with Biomed Central and every scientist can read your work free of charge

"BioMed Central will be the most significant development for disseminating the results of biomedical research in our lifetime. "

Sir Paul Nurse, Cancer Research UK

Your research papers will be:

- available free of charge to the entire biomedical community

- peer reviewed and published immediately upon acceptance

- cited in PubMed and archived on PubMed Central

- yours - you keep the copyright
BioMedcentral 